\title{
A probabilistic view on recent and near future climate change in Sweden
}

\author{
By JOUNI RÄISÄNEN* and HANS ALEXANDERSSON, Swedish Meteorological and Hydrological \\ Institute, S-60176 Norrköping, Sweden
}

(Manuscript received 2 July 2002; in final form 24 October 2002)

\begin{abstract}
The decade 1991-2000 was warm and wet in Sweden, with 10-station mean temperature $0.8^{\circ} \mathrm{C}$ above and 20-station mean precipitation 6\% above the mean for 1961-1990. Here we study the question if such changes should be seen as a symptom of anthropogenic climate change or if they might be of purely natural origin. Using the control simulations of 19 atmosphere-ocean general circulation models and taking into account differences between the simulated and observed interannual variability, we estimate that the recent increase in temperature and that in precipitation had both about a $6-7 \%$ chance to occur solely as a result of natural variability. Using the corresponding simulations with increasing $\mathrm{CO}_{2}$, we further estimate that the anthropogenic forcing raised the probability of the observed changes to occur to $23 \%$ for the increase in temperature and to $14 \%$ for the increase in precipitation. About half of the warming and about $30 \%$ of the increase in precipitation appear to be explained by anthropogenic forcing. The seasonal aspects of observed and simulated climate change are also discussed, with special emphasis on winter, when the observed warming has been much larger than expected from the model simulations. Finally, a probabilistic forecast for the Swedish climate in the first decade of the 21st century suggests a $95 \%(87 \%)$ possibility of warmer (wetter) annual mean conditions than in 19611990 on the average. One of the caveats in our analysis is that the model simulations exclude variations in solar and volcanic activity, the effects of which might not be fully covered by our rescaling of interannual variability.
\end{abstract}

\section{Introduction}

Accumulating observational evidence together with model-based studies is making it increasingly clear that the global climate is affected by human activity (Mitchell et al., 2001). The observed $0.6 \pm 0.2{ }^{\circ} \mathrm{C}$ increase in global mean surface air temperature during the 20th century is, in the light of model simulations, too large to be explained by internally generated natural variability alone. Furthermore, while natural external forcing from changes in solar and volcanic activity may have caused a substantial part of the warming before about 1945, it does not appear to explain the continued warming in the latter part of the century (Stott

\footnotetext{
*Corresponding author. e-mail: jouni.raisanen@helsinki.fi
}

et al., 2000). As formulated by the Intergovernmental Panel on Climate Change (Houghton et al., 2001, p. 10), "most of the observed warming over the last 50 years is likely to have been due to the increase in greenhouse gas concentrations." This conclusion is supported not only by the time evolution of the global mean surface air temperature, but also by the largescale geographical and vertical (tropospheric warming and stratospheric cooling) distribution of the changes.

The reasonably well demonstrated impact on the global climate implies that the increase in greenhouse gases (and other anthropogenic changes, such as increases in aerosol concentrations) also affects regional climates all over the world. However, a formal detection (i.e., separation from internal variability) of climate changes and their attribution to human activity is more difficult on regional than on global scales. 
For one thing, the amplitude of internal variability increases with decreasing scale. For the other, modelbased estimates of how much increasing greenhouse gases should affect climate also become less consistent toward smaller scales (e.g., Räisänen, 2001). In spite of this, detection and attribution of regional climate changes are of great interest. During the last few decades, many parts of the world have experienced an increase in temperature and/or changes in other climate elements (such as precipitation) that qualitatively coincide with the expected effects of increasing greenhouse gases. The question that arises is if such variations should be seen as a first sign of a long-lived man-made climate change, or if they might still be an expression of natural variability that might reverse with time.

As a particular example, we consider in this paper the recent warming and increase in precipitation in Sweden. As reported by Alexandersson and Eggertsson Karlström (2001), the decade 1991-2000 was in Sweden $0.8{ }^{\circ} \mathrm{C}$ warmer than the preceding $30-$ yr period, with the largest difference (almost $2{ }^{\circ} \mathrm{C}$ ) in winter temperatures. Precipitation was also abundant, especially in the two exceptionally wet years 1998 and 2000 , and its all-station decadal mean exceeded the mean for $1961-1990$ by $8 \%$.

The approach in this study is similar to that commonly used in studies related to the detection and attribution of global climate change. We begin by describing the recent observed climate changes and put them in the context of the instrumental record for the last $140 \mathrm{yr}$ (section 2). However, observations alone do not provide a sufficient basis for assessing the origin of the recent changes. The observational record is too short to give a good estimate of long-term unforced climate variability, and its interpretation is further complicated by the presence of several external (natural and anthropogenic) forcing agents capable of altering the climate. The remainder of the paper therefore compares the recent changes with the results of a large set of climate models (introduced in section 3 ).

In section 4, the model control simulations are used to estimate the probability for obtaining the observed (or larger) changes purely as a result of natural climate variability. Then (in section 5), the probability distribution of 10-yr-30-yr climate differences is recalculated for the case in which anthropogenic radiative forcing (represented in the models crudely by an increase in $\mathrm{CO}_{2}$ ) is also included. If the observed changes appear less unusual against this probability distribution than against the one derived from the control simulations, one can claim that the addition of the forcing improves the agreement with observations. This generally turns out to be the case. However, some of the observed changes appear too large to have been caused by the anthropogenic forcing alone, assuming that the model simulations do not underestimate the effects of this forcing. In particular, the observed warming in winter is so much larger than that on the average expected from the models that it deserves some further discussion in section 6. Before the conclusions (section 8), a probabilistic forecast is given for the climate in Sweden in the decade 2001-2010 (section 7).

\section{Observed climate changes}

Time series of "Sweden mean" annual temperature and precipitation from 1860 to 2001 are shown in Figs. 1a and b. Decadal means of the same time series (from 1861-1870 to 1991-2000) are given in Figs. 1c and d. Temperature is averaged over 10 and precipitation over 20 stations evenly distributed over the country. All series have been adjusted for detected inhomogenities (Moberg and Alexandersson, 1997; Alexandersson, 2001). However, for precipitation homogenisation is especially difficult, because changes in instrumentation have sometimes occurred quasisimultaneously at a large number of stations. Nevertheless, there are strong reasons to believe that the results for at least the last four decades closely portray the true variations in climate.

The two time series both show a long-term increase. The best-fit linear temperature and precipitation trends from 1860 to 2001 are $1.33^{\circ} \mathrm{C}$ and $22.7 \%$ of the mean for 1860-2001, respectively. Climate model control simulations suggest that such large trends are unlikely to arise from internal climate variability alone (end of section 4). However, at least two complications prevent a straightforward attribution of these trends to the anthropogenic increase in greenhouse gases.

First, most of the long-term increase in temperature took place during the late 19th and early 20th centuries, when the increase in $\mathrm{CO}_{2}$ and other atmospheric greenhouse gases was still relatively small. In fact, the decade 1931-1940 was nearly as warm as 1991-2000. This early peak in Sweden mean temperature is stronger than, but almost coincident in time with, a temporary maximum in global mean temperature in the early 1940s (Folland et al., 2001). The peak in global mean temperature could have resulted from an extreme phase of unforced climate variability 

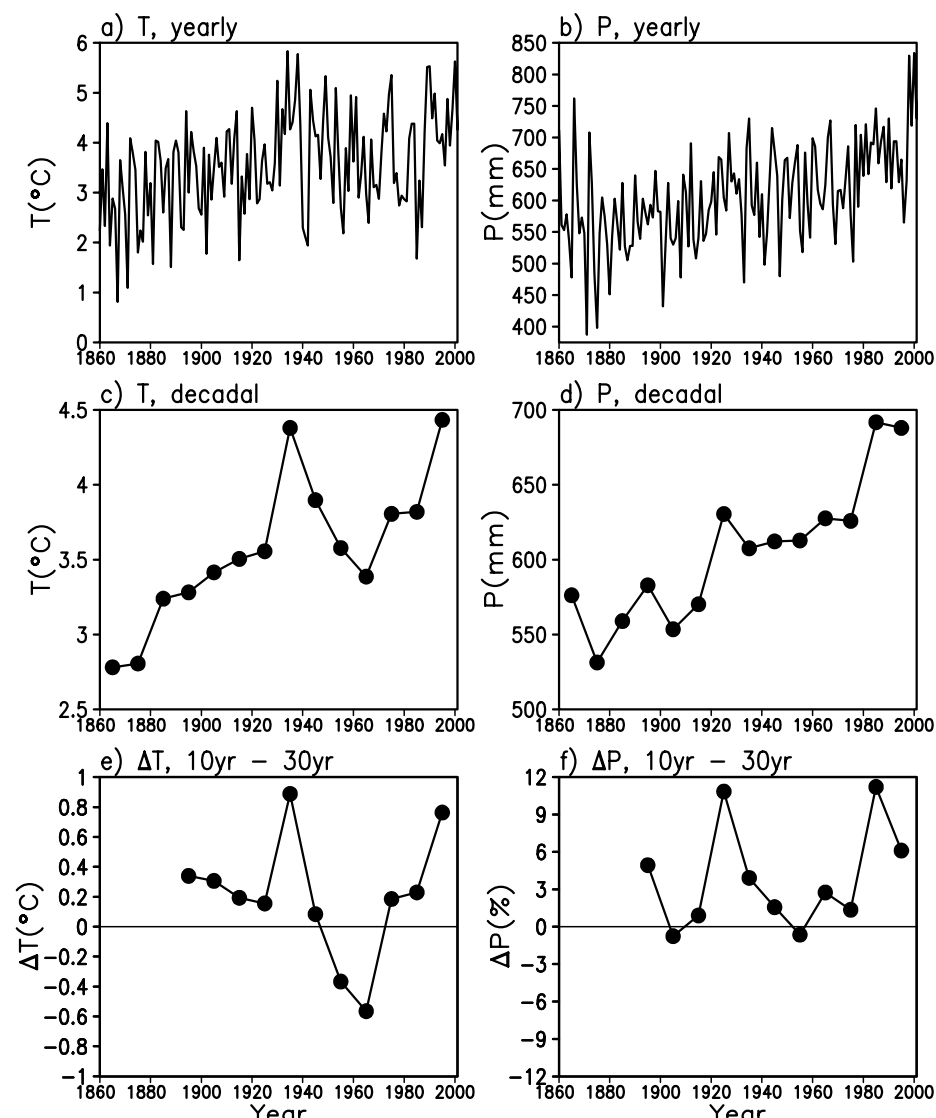

Fig. 1. Observed 10-station mean temperature (left) and 20-station mean precipitation (right) in Sweden. Top: yearly values, 1860-2001. Middle: decadal means. Bottom: Difference between the decade given on the abscissa and the mean for the previous three decades. For example, the last point on the right in (e) gives the temperature difference 1991-2000 minus 1961-1990.

with some support from increase in greenhouse gases (Delworth and Knutson, 2000), but the simulations of Stott et al. (2000) suggest that variations in solar and volcanic activity were also involved. Similar arguments apply to the warm 1930s in Sweden: the exact reasons are unknown.

Second, the quality of observations during the early part of the instrumental record may be of concern, especially regarding precipitation. The improvement of rain gauges has gradually increased the fraction of actual precipitation caught in the measurements. It is not certain that the homogenisation procedure applied to the precipitation observations has removed this effect completely. Thus, the increase in precipitation seen in Figs. $1 \mathrm{~b}$ and $1 \mathrm{~d}$ may overestimate the real increase.
The interpretation of these long time series will deserve further study. In this paper, however, we focus our attention to the late 20th century, when the quality of observations was presumably highest and the anthropogenic increase in greenhouse gases is believed to have been the main external factor affecting the global climate (Stott et al., 2000; Houghton et al., 2001). Our study was initially inspired by Alexandersson and Eggertsson Karlström (2001), who found the decade 1991-2000 to have been substantially warmer and wetter than the previous 30-yr normal period 19611990. The question that we try to address is therefore whether the warmth and the wetness of the 1990s (relative to the previous 30-yr period) was more likely of natural or of anthropogenic origin. 
In the context of the 140-yr time series, the 1990s were a warm and wet decade but not outside the earlier limits of variability. The 1930 s were as warm as the 1990s and the 1980s as a whole slightly wetter (although without extremely wet single years like 1998 and 2000). The climate change statistics of Alexandersson and Eggertsson Karlström (2001), i.e., the difference between the decadal mean climate and the previous 30-yr mean, leads to similar conclusions (Figs. 1e and f). The differences between 1991-2000 and 19611990 are large but not unprecedented. In particular, both the temperature and precipitation changes from 1901-1930 to 1931-1940 were even larger. The instrumental record alone therefore gives no sufficient grounds to claim that the Swedish climate in the 1990s was affected by human activity. On the other hand, it also provides no evidence against this possibility. The model-based results in the next sections suggest that the likelihood of the occurrence of such a warm and wet decade was substantially enhanced by greenhouse gas forcing.

The observed seasonal and annual changes in the 10 -station mean temperature and 20-station mean precipitation from 1961-1990 to 1991-2000 are given in the first row of Table 1. Temperature has risen only slightly in summer and autumn, but more substantially in spring and especially in winter. Precipitation has increased in all seasons excluding autumn. These 20 -station precipitation changes differ slightly from the all-station means in Alexandersson and Eggertsson Karlström (2001) (who report an annual precipitation increase of $8 \%$ instead of $6.1 \%$ ), but the agreement on the temperature changes is almost perfect.

An issue that we leave for further study is whether a simultaneous (rather than separate) analysis of the Sweden mean temperature and precipitation changes would give significant new information. Power et al. (1998) applied such an approach to climate changes in Australia, where the interannual variations of temperature and precipitation tend to be anticorrelated. By demonstrating that the recent warming was not associated with reduced precipitation, they strengthened the case that the warming was unusual. In Sweden the situation is different. With the exception of summer, the variations of temperature and precipitation tend to be in rather than out of phase, although the correlation on the interannual time scale is relatively weak ( 0.2 for the annual mean values, when calculated from detrended time series for 1860-2001). The parallel increases in temperature and precipitation are in this respect not surprising, even though it may still be more improbable to get, by chance, a large change in both parameters simultaneously than in either of them separately.

\section{Model data}

In the next three sections, we compare the recent observed climate changes with climate model simulations. We use the results of 19 atmosphere-ocean general circulation models (Table 1 of Räisänen, 2002) participating in CMIP2, the second phase of the Coupled Model Intercomparison Project (Meehl et al., 2000). For each model, two 80-yr simulations are available: a control run with constant ("present-day") $\mathrm{CO}_{2}$, and a greenhouse run in which $\mathrm{CO}_{2}$ increases by $1 \%$ per year compound, doubling in $70 \mathrm{yr}$. As radiative forcing increases with the logarithm of the $\mathrm{CO}_{2}$ concentration (Ramaswamy et al., 2001), this exponential increase in $\mathrm{CO}_{2}$ gives a linear increase in forcing. The greenhouse run global mean temperature is also in most models a nearly linear function of time, except for unforced interannual variability superimposed on the long-term trend.

From each $80-y r$ run, one can select 41 overlapping 40 -yr periods and calculate the difference in climate between the last 10 and the first $30 \mathrm{yr}$. This yields a total of $19 \times 41=779$ differences for both the control and the greenhouse runs, even though the number of independent data is much smaller. The first set

Table 1. Observed changes in Sweden mean temperature and precipitation from 1961-1990 to 1991-2000 (top), and the changes expected from anthropogenic climate forcing during this period in light of the CMIP2 simulations (bottom; see Section 5)

\begin{tabular}{|c|c|c|c|c|c|c|c|c|c|c|}
\hline & \multicolumn{5}{|c|}{ Temperature change $\left({ }^{\circ} \mathrm{C}\right)$} & \multicolumn{5}{|c|}{ Precipitation change $(\%)$} \\
\hline & DJF & MAM & JJA & SON & Annual & $\mathrm{DJF}$ & MAM & JJA & SON & Annual \\
\hline Observed & 1.97 & 0.68 & 0.21 & 0.18 & 0.76 & 11.3 & 9.1 & 10.3 & -3.6 & 6.1 \\
\hline CMIP2 & 0.51 & 0.39 & 0.32 & 0.38 & 0.40 & 2.4 & 1.8 & 0.8 & 1.9 & 1.7 \\
\hline
\end{tabular}


of differences can be used to estimate the probability distribution of 10-yr minus 30-yr "climate changes" in the absence of external forcing. It is important to note, though, that the simulated variability may differ from that in nature (Allen and Tett, 1999), both because models may misrepresent the internally generated variability in the real climate system and because they have no variations in solar and volcanic activity. The second set of differences is used to study how the probability distribution would change as a result of increasing greenhouse gases. When doing this, however, an additional adjustment is needed because the forcing in the models is stronger than the actual anthropogenic climate forcing in the last few decades (see section 5).

\section{Climate variability estimated from the CMIP2 control runs}

The control run frequency distributions of the 10-yr minus 30-yr Sweden mean temperature and precipitation differences are compared with the observed 1991-2000 minus 1961-1990 differences in the left part of Fig. 2. None of the observed changes is totally outside the simulated values, but several of them ap- pear in this context unusual. The increases in winter and annual mean temperature and winter, summer and annual precipitation are all within the top $5 \%$ of the corresponding control run distributions.

However, caveats exist. First, the control simulations show on the average a slight decreasing trend in temperature and precipitation. Regardless of if this trend results from genuine climate drift (i.e., cooling and drying caused by a conflict between the model physics and the control run initial conditions) or if it is purely accidental, it acts to reduce the frequency of large positive 10-yr minus 30-yr differences. Second and more importantly, the amplitude of the simulated variability may differ from that in nature. In particular, if the models underestimate the variability, this will make the observed changes to appear more improbable than they actually are.

It is difficult to estimate the amplitude of natural interdecadal climate variability from observations. The instrumental record is too short to provide statistically robust estimates, in addition to which it is contaminated by anthropogenic forcing. However, these problems both diminish when considering variability on shorter time scales, which provide a larger sample size and where the truly unforced variability is stronger.

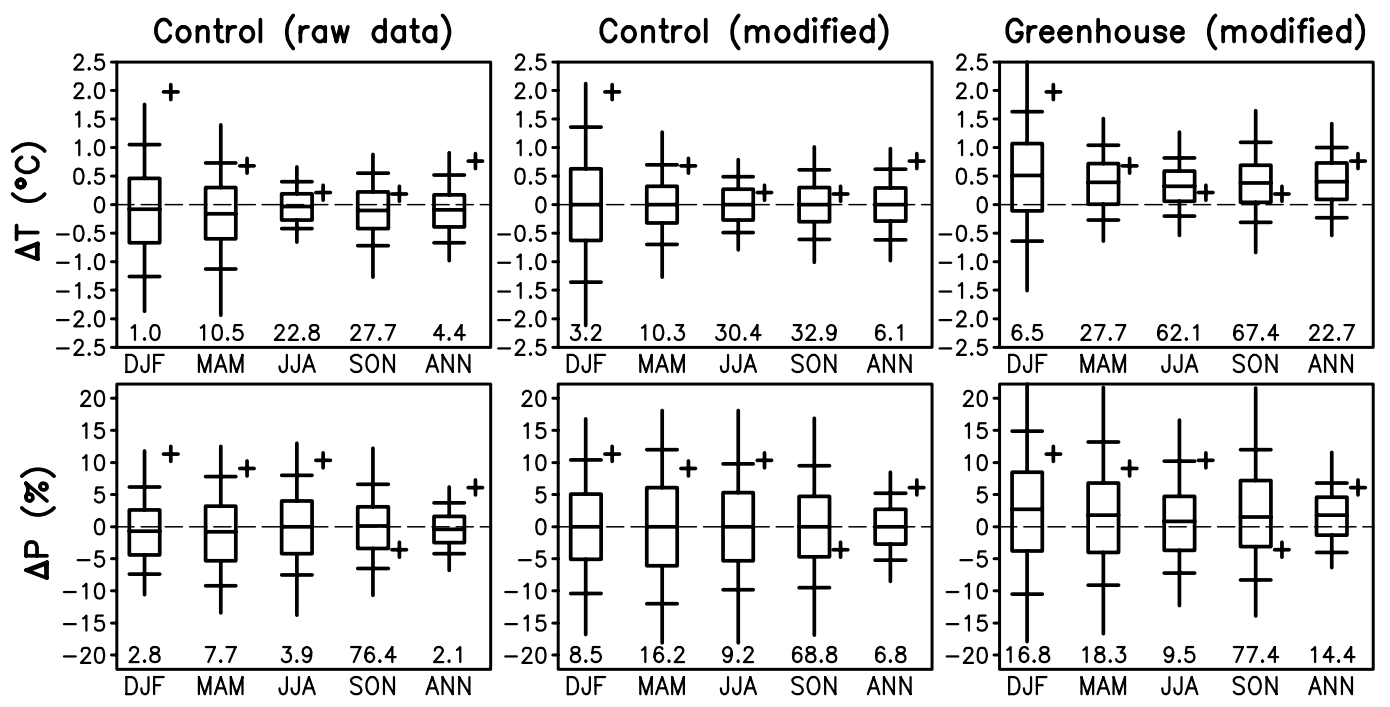

Fig. 2. Probability distribution of 10-yr minus 30-yr Sweden mean temperature (top) and precipitation (bottom) differences, as estimated from CMIP2 data. Results are shown for the control runs as such (on the left), for the control runs after modification (middle) and for the modified greenhouse runs (right). Each whisker shows the 2nd (bottom), 10th (lowermost cross-line), 25th (bottom of box), 75th (top of box), 90th (uppermost cross-line) and 98th (top) percentiles and the mean (cross-line within the box) of the distribution. The plus signs (+) depict the observed changes from 1961-1990 to 1991-2000. The numeric values in the bottom give the percent fraction of simulated differences above the observed change. 
Table 2. Interannual standard deviation of Sweden mean temperature and precipitation in the CMIP 2 control runs and as estimated from observations, and the ratio between the two.

\begin{tabular}{|c|c|c|c|c|c|c|c|c|c|c|}
\hline & \multicolumn{5}{|c|}{ Temperature $\left({ }^{\circ} \mathrm{C}\right)$} & \multicolumn{5}{|c|}{ Precipitation ( $\%$ of $40-y r$ mean) } \\
\hline & DJF & MAM & JJA & SON & Annual & DJF & MAM & JJA & SON & Annual \\
\hline CMIP2 & 2.07 & 1.62 & 0.81 & 1.26 & 0.94 & 14.1 & 16.5 & 16.1 & 13.8 & 7.7 \\
\hline Observed & 2.38 & 1.21 & 0.96 & 1.16 & 0.97 & 21.3 & 23.1 & 20.9 & 20.4 & 10.3 \\
\hline CMIP2/Obs & 0.87 & 1.34 & 0.84 & 1.08 & 0.97 & 0.66 & 0.71 & 0.77 & 0.68 & 0.75 \\
\hline
\end{tabular}

The observed standard deviation was derived by first detrending the temperature and precipitation time series for the periods 1921-1960 and 1961-2000 separately (to eliminate long-term trends associated with anthropogenic forcing), and by then calculating the variance in these two periods and averaging it before taking the square root. The CMIP2 standard deviation was calculated in the same way, by averaging the detrended variance over the 19 models and two 40 -yr periods in each model.

The simulated interannual standard deviations of Sweden mean temperature and precipitation are compared in Table 2 with observational estimates for the last $80 \mathrm{yr}$, when the data quality is expected to have been highest (see the table caption for details). The simulated temperature variability appears reasonably realistic. The models seem to underestimate the variability slightly in winter and summer, but they tend to overestimate it in spring. However, precipitation variability in the models appears systematically too small, being of the order of $70 \%$ of the observed variability. Assuming that the variability in the models has a temporal autocorrelation structure similar to that in the real world (which, as discussed below, is a nontrivial assumption), an under(over)estimate of interannual variability implies an equally large under(over)estimate of interdecadal variability.

To cope with these two issues, two adjustments to the probability distributions were made. To remove the bias associated with the average cooling and drying trend, the 779 original 10-yr minus 30-yr differences were complemented with the 779 negatives of these differences, to get a total of 1558 differences symmetrically distributed around zero. Second, to correct for the suspected errors in variance, each 41-member series of 10-yr minus 30-yr differences was replaced with a new series with the same mean and a factor of

$C=\frac{B-0.12}{1-0.12}$

larger or smaller variance. Here $B$ is the ratio between the observed and average simulated interannual variances (derived from the values in Table 2), which is assumed to be representative even on the interdecadal time scale. For simplicity, the same value of $B$ is used for all models; evaluating $B$ separately for different models yielded only small differences in the result- ing 19-model ensemble frequency distributions. Details of the modification procedure are given in the Appendix. Equation (1) is a special case of eq. (A10), with $A=1$.

Applying this procedure to the control runs, the frequency distributions shown in the midcolumn of Fig. 2 were obtained. The distributions for precipitation change are systematically wider than the ones derived directly from the control run time series, which makes the observed increases to appear less extreme. The results for temperature are affected much less. The inferred probability for the observed annual temperature and precipitation increases is now 6-7\%. The probability for the observed winter warming still appears low (3\%), even though it is not unexceptional that such a low value occurs in one of the four seasons.

The CMIP2 control runs exclude variations in solar and volcanic activity. To the extent that these external factors only affect the total amount of natural variability in the real world (as measured by the interannual variance or standard deviation) this deficiency is implicitly taken into account by the variance adjustment described above. If they also lengthen the characteristic time scale of the variability, the situation becomes more problematic. Recent experiments with the HadCM3 climate model indicate that this is likely to be the case. Collins et al. (2002) compared the temperature variability in a long HadCM3 control run (with no external forcing) with an ensemble of four simulations forced with estimated changes in solar and volcanic activity (but no anthropogenic forcing) between 1860 and 1997. In the latter set of simulations, the total amount of interannual variability was larger than in the unforced control run and its spectrum was redder, that is, the increase in variance was largest on decadal and longer time scales. On the other hand, these two effects were both less pronounced on small 
than on large horizontal scales. In northern Europe, the results of the forced and unforced simulations were, perhaps incidentally, almost identical (see Fig. 16 and Tables 3 and 4 in Collins et al., 2002). These results suggest that the lack of natural forcing in the CMIP2 control runs may lead to an underestimate of interdecadal variability in the Swedish climate, even when an adjustment is made to remove biases in the total interannual variability. The effect is likely to be relatively small, but additional model simulations would be needed to quantify it with any confidence.

The long-term temperature and precipitation trends discussed in section 2 have a higher statistical significance than the differences between 1991-2000 and 1961-1990. The largest 80-yr trend in Sweden annual mean temperature in the 19 CMIP2 control runs is (in absolute value) $0.92{ }^{\circ} \mathrm{C}$, and the largest trend in annual precipitation $9.6 \%$. Both are substantially smaller than the observed 142-yr trends from 1860 to $2001\left(1.33{ }^{\circ} \mathrm{C}\right.$ and $22.7 \%$ ). Since the simulations are shorter than the observational record, the numeric values are not directly comparable. However, as theoretically expected for randomly generated trends, the trends in the CMIP2 control runs decrease in magnitude with increasing period length (even when they are expressed as the difference between the two ends of the period, rather than in ${ }^{\circ} \mathrm{C}$ or $\%$ per year). Even when accounting for the differences between the simulated and observed interannual variability, this suggests that the observed increases in temperature and precipitation since 1860 are very unlikely to have resulted from pure chance. However, as already noted in section 2, the trends in the early part of the observational record may have been affected more by changes in solar and volcanic activity than by the increase in greenhouse gases.

\section{Observed changes versus model response to increasing $\mathrm{CO}_{2}$}

Although the Swedish climate changed considerably from 1961-1990 to 1991-2000, neither the longer observational record nor the CMIP2 control runs can disprove the possibility that the changes resulted from natural variability alone. On the other hand, the strong indications that the global mean climate is affected by anthropogenic forcing make it implausible to expect that the Swedish climate would be completely unaffected. The question is, how much? Is anthropogenic forcing likely to have been a minor or the major contributor to the recent changes?
To study this issue, the CMIP2 greenhouse runs were used. As for the control runs, a sample of $19 \times$ $41=779$ differences is available to estimate the probability distribution of $10-\mathrm{yr}$ minus $30-\mathrm{yr}$ climate changes in the presence of increasing greenhouse gases. However, the $1 \%$ per year increase in $\mathrm{CO}_{2}$ in the CMIP2 experiments exaggerates the recent anthropogenic forcing on climate. To account approximately for this, a scaling based on the global mean radiative forcing was used. The best, although quite uncertain, estimate for the increase in the total anthropogenic radiative forcing from 1961-1990 to $1991-2000$ is $0.6 \mathrm{~W} \mathrm{~m}^{-2}$ (Table 3 ). This is approximately $55 \%$ of the $1.06 \mathrm{~W} \mathrm{~m}^{-2}$ increase in forcing that a $1 \%$ per year increase in $\mathrm{CO}_{2}$ would have produced in the same time. Thus, for each of the 19 greenhouse runs, the original sample of 41 10-yr minus 30-yr differences was perturbed by multiplying the mean by the factor $A=0.55$ and changing the variance according to eq. (A10).

The total anthropogenic radiative forcing includes, in addition to the effects of $\mathrm{CO}_{2}$ and other well mixed greenhouse gases, contributions from changes in stratospheric and tropospheric ozone and several types of aerosols. The response of regional climates to this combination of forcings may differ from the response to increasing $\mathrm{CO}_{2}$, even when the global mean forcing is the same. However, this is likely to be a smaller uncertainty than the differences in climate response between different models (Giorgi and Fransisco, 2000; Cubasch et al., 2001).

The resulting probability distributions are shown in the right part of Fig. 2. The increasing $\mathrm{CO}_{2}$ causes an upward shift in both the temperature and precipitation change distributions, although the shift is very small in the case of summer precipitation. However, the average increase in annual mean temperature is only a half, and the increase in precipitation only $30 \%$ of the observed change from 1961-1990 to 1991-2000 (see also Table 1). If the models do not underestimate the sensitivity of Swedish climate to increasing greenhouse gases, this indicates that the observed changes have been amplified by internal climate variability and/or by forcing agents excluded from the simulations. One should also note that the observed $6 \%$ increase in annual precipitation is small compared with the absolute errors in the measurements. Although the time series have been homogenised, this calls for some additional caution in interpreting the results.

Nonetheless, a comparison between the results in the middle and the right part of Fig. 2 suggests that the chance of getting the observed large changes in 
temperature and precipitation was substantially enhanced by the increase in greenhouse gases. The inferred probability for the observed annual mean warming increases by a factor of four to $23 \%$, and that for the observed increase in annual precipitation by a factor of two to $14 \%$. As a whole, the probability values derived from the greenhouse runs seem less exceptional (i.e., generally closer to $50 \%$ ) than those derived from the control runs.

\section{Changes in winter temperature and circulation}

The observed change that comes closest to the ends of the (modified) greenhouse run probability distributions is the large wintertime warming $\left(2.0^{\circ} \mathrm{C}\right)$, which exceeds the central model estimate of $0.5^{\circ} \mathrm{C}$ by a factor of four. This difference is consistent with the difference between the observed and average model-derived changes in winter mean sea level pressure. The observed changes from 1961-1990 to 1991-2000, taken here from the NCEP reanalysis (Kalnay et al., 1996; Kistler et al., 2001) exhibit a substantial north-south gradient, which indicates increased warm advection from the Atlantic Ocean to northern Europe (Fig. 3a). By contrast, the average scaled model-simulated pressure changes, estimated here from 17 models excluding two (CCSR2 and MRI2) with no pressure data available, are very small (Fig. 3b).

A rough estimate of the contribution of the pressure change to the observed wintertime warming was derived using the traditional Portugal minus Iceland North Atlantic Oscillation (NAO) index (e.g., Hurrell, 1995). The average December-January-February mean pressure difference between the two grid boxes $\left(7.5^{\circ} \mathrm{W}, 40^{\circ} \mathrm{N}\right)$ and $\left(22.5^{\circ} \mathrm{W}, 65^{\circ} \mathrm{N}\right)$ increased accord- ing to the NCEP reanalysis by $6.2 \mathrm{hPa}$ from 19611990 to $1991-2000$, from 18.2 to $24.4 \mathrm{hPa}$. The interannual variations of this index are strongly correlated with winter mean temperature in Sweden $(r=$ 0.75 for the period 1948-2001, regardless of if the two time series are used as such or if they are detrended before the calculation). Linear regression suggests a $0.22{ }^{\circ} \mathrm{C}$ increase in Sweden winter mean temperature for a $1 \mathrm{hPa}$ increase in this index, or $1.4{ }^{\circ} \mathrm{C}$ for the observed $6.2 \mathrm{hPa}$ change. The part of the observed warming that is not linearly related to NAO $\left(0.6{ }^{\circ} \mathrm{C}\right)$ is in good agreement with the average model-derived $0.5^{\circ} \mathrm{C}$ warming. The contribution of the NAO change to the latter figure is negligible, since the average scaled increase in the mentioned pressure difference in the CMIP2 greenhouse runs is only $0.1 \mathrm{hPa}$. The results for the individual models vary, but even in the ECHAM3 model in which the average (41-case mean) scaled NAO increase is largest, this only amounts to $1.3 \mathrm{hPa}$.

As noticed in other studies (Folland et al., 2001 and references therein), the recent change in the winter NAO index appears to be at the outer limits of what can be expected from internal variability alone. In fact, the CMIP2 control runs include no single occasion with such a large $10-y r$ minus $30-y r$ mean increase in the winter NAO index, although there are a few cases with a larger decrease. Most models underestimate the interannual variance of the NAO index, on the average by $30 \%$, but even when this is adjusted for using eq. (1), the inferred probability of a $6.2 \mathrm{hPa}$ increase only increases to $3 \%$. The corresponding probability derived from the scaled greenhouse runs is $5 \%$. This leaves three possibilities. The first is that the observed increase in NAO is only an unusual event associated with internal climate variability. The second is that it is at least partly a response to increasing greenhouse gases,

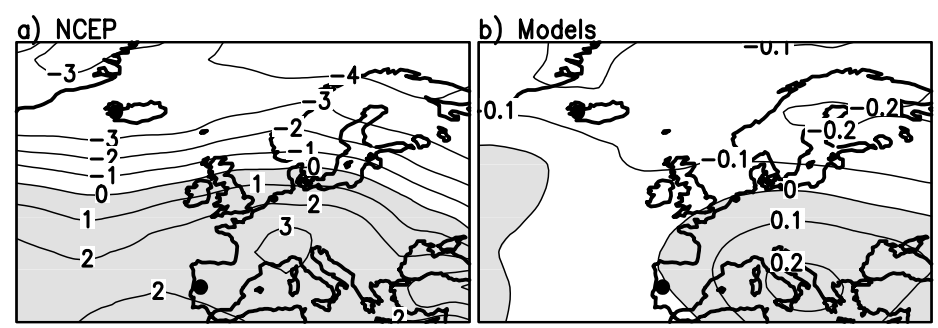

Fig. 3. (a) Change in December-February mean sea level pressure from 1961-1990 to 1991-2000 from the NCEP reanalysis. (b) The change expected from the CMIP2 greenhouse runs (see text). Contour interval is $1 \mathrm{hPa}$ in (a) and $0.1 \mathrm{hPa}$ in (b). The two closed circles indicate the grid points used for calculating the NAO index. 
which is not well captured by the CMIP2 ensemble, possibly because the stratosphere is represented too crudely in these models (Shindell et al., 1999). Third, the change might have been affected by other changes in external conditions such as the stratospheric ozone depletion (see the discussion in Stocker et al., 2001). It is still unclear which of these possibilities is closest to the truth.

\section{A probabilistic forecast for the decade 2001-2010}

The methods developed above can be used to generate a probabilistic forecast of near future climate. Following the convention to use $30-\mathrm{yr}$ means to describe the "present" climate, we select the period 1971-2000 as our baseline and try to predict how the Swedish climate in the ongoing decade (2001-2010) will differ from this. This calculation is identical to that in section 5 , except for an adjustment in the scaling factor $A$ in eq. (A10). The central IPCC estimate for the increase in anthropogenic radiative forcing from the 30 -yr mean 1971-2000 to the 10-yr mean 2001-2010 is approximately $0.7 \mathrm{~W} \mathrm{~m}^{-2}$ (Table 3 ), based on projected near-

Table 3. Best estimate time and global mean radiative forcing due to anthropogenic changes in atmospheric composition since the preindustrial era (based on Fig. 19 of Houghton et al., 2001).

\begin{tabular}{lc}
\hline Years & Forcing $\left(\mathrm{W} \mathrm{m}^{-2}\right)$ \\
\hline $1961-1990$ & 0.6 \\
$1971-2000$ & 0.85 \\
$1991-2000$ & 1.2 \\
$2001-2010$ & 1.55 \\
\hline
\end{tabular}

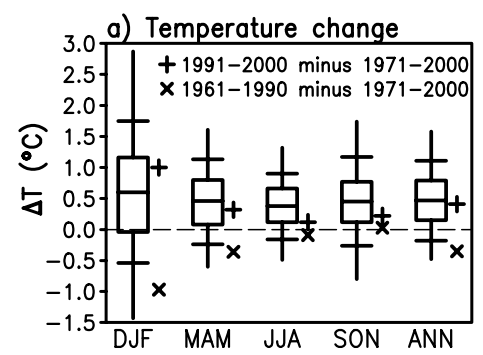

future changes in greenhouse gas and aerosol concentrations. Thus, we use $A=0.65(\approx 0.7 / 1.06)$ in this case.

Figure 4 shows the resulting probability distributions for Sweden mean temperature and precipitation in 2001-2010, expressed as differences from the means for 1971-2000. For clarity, the figure also includes the observed temperatures and precipitation for the periods 1961-1990 (crosses) and 1991-2000 (plus signs), likewise expressed as deviations from the 1971-2000 baseline. For example, the best estimate from this exercise is that winters in 2001-2010 will be $0.6{ }^{\circ} \mathrm{C}$ warmer than the mean for 1971-2000. This is $0.4{ }^{\circ} \mathrm{C}$ colder than the mean for 1991-2000, but $1.6^{\circ} \mathrm{C}$ warmer than the mean for 1961-1990.

As the best estimate, the calculation suggests that the annual mean temperature in 2001-2010 should be $0.5{ }^{\circ} \mathrm{C}$ higher than that for $1971-2000$ (or $0.8{ }^{\circ} \mathrm{C}$ higher than that for 1961-1990), but almost identical with $\left(0.1{ }^{\circ} \mathrm{C}\right.$ higher than $)$ that in the decade 1991-2000. Similarly, the annual mean precipitation in 2001-2010 is projected to be $2 \%$ higher than in 1971-2000 (or 5\% higher than 1961-1990), but almost the same as (1\% lower than) in 1991-2000. The details for the individual seasons vary, but in general it appears likely that the temperature and precipitation climate in 2001-2010 will be closer to that in 19912000 than to that in the standard normal period 19611990.

It is essential to note the uncertainty in these best estimates. The probability distributions shown in Fig. 4 are wide, which reflects both the unpredictable effects of natural variability and (although to a lesser extent) the differences between different models in their sensitivity to increasing $\mathrm{CO}_{2}$. The central $80 \%$ confidence interval (from the 10th to the 90th percentile) for the

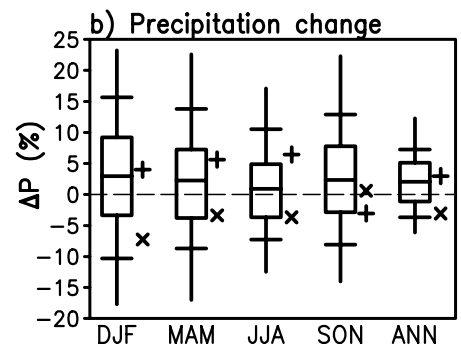

Fig. 4. Probabilistic forecast for Sweden mean temperature (a) and precipitation (b) in the decade 2001-2010, expressed as deviation from the mean of 1971-2000. Whiskers as in Fig. 2. The plus signs (+) show the difference 1991-2000 minus 1971-2000 and the crosses $(\times)$ the difference 1961-1990 minus 1971-2000.

Tellus 55A (2003), 2 
Table 4. Estimated probability that the period 2001-2010 will be warmer (left half) or wetter (right half) than each of the three baseline periods 1991-2000, 1971-2000 and 1961-1990.

\begin{tabular}{|c|c|c|c|c|c|c|c|c|c|c|}
\hline & \multicolumn{5}{|c|}{$\begin{array}{l}\text { Probability }(\%) \text { of temperature increase } \\
\text { relative to the baseline on the left }\end{array}$} & \multicolumn{5}{|c|}{$\begin{array}{l}\text { Probability }(\%) \text { of precipitation increase } \\
\text { relative to the baseline on the left }\end{array}$} \\
\hline & DJF & MAM & JJA & SON & $\overline{\text { Annual }}$ & DJF & MAM & JJA & SON & Annual \\
\hline 1991-2000 & 33 & 61 & 74 & 69 & 55 & 45 & 34 & 21 & 76 & 43 \\
\hline $1971-2000$ & 73 & 79 & 83 & 80 & 83 & 63 & 60 & 51 & 60 & 68 \\
\hline 1961-1990 & 95 & 94 & 88 & 79 & 95 & 85 & 74 & 75 & 57 & 87 \\
\hline
\end{tabular}

change in annual mean temperature has a width of $1.3{ }^{\circ} \mathrm{C}$ (about $0.65{ }^{\circ} \mathrm{C}$ on the both sides of the best estimate), and the corresponding interval for the change in annual precipitation a width of $11 \%$. Uncertainty in seasonal values is generally larger. In particular, the same $80 \%$ interval for winter temperature extends over $2.3{ }^{\circ} \mathrm{C}$, or about $1.15^{\circ} \mathrm{C}$ to the both sides of the best estimate.

Table 4 expresses these probabilistic results in another format. The first line shows the estimated probability that temperature and precipitation in 2001-2010 will be higher than in 1991-2000, and the next two lines the probabilities that they will be higher relative to 1971-2000 and 1961-1990, respectively. One can evidently not say much of the likely sign of differences between 2001-2010 and 1991-2000. The probabilities for the seasonal and annual temperature and precipitation increases all vary within $21-76 \%$. However, the situation changes somewhat when comparing 20012010 with the earlier 30-yr periods 1971-2000 and 1961-1990. For example, the calculation indicates an $83 \%$ probability of annual mean warming relative to 1971-2000, and a 95\% probability of warming relative to 1961-1990. It also seems very unlikely that the winter and spring temperatures in 2001-2010 would be lower than those in 1961-1990. The predictions of precipitation change are less certain, even though the calculation suggests an $87 \%$ probability that annual mean precipitation in 2001-2010 will exceed that in 1961-1990. This is because, in the models, the impact of increasing $\mathrm{CO}_{2}$ on precipitation is smaller relative to internal variability than the impact on temperature.

The probability distributions derived above are more likely too narrow than too wide. Thus, for example, the chance that the actual temperature and precipitation changes will be outside the central $80 \%$ confidence interval might be larger than $20 \%$. There are several simplifications in our analysis that necessitate this reservation: (a) The CMIP2 simulations exclude variations in solar and volcanic activity. This might make them to underestimate natural variability on interdecadal time scales, despite the adjustment used to make the total interannual variability consistent with observations.

(b) Anthropogenic climate forcing is approximated by an increase in $\mathrm{CO}_{2}$ only, assuming that the climate response only depends on the global mean of the forcing.

(c) The assumed $0.7 \mathrm{~W} \mathrm{~m}^{-2}$ change in radiative forcing is an uncertain number. This is the case partly because the atmospheric composition in the decade 2001-2010 is still not exactly known, but more importantly because there is substantial scientific uncertainty related to some components of the forcing, most notably the direct and indirect effects of aerosols.

(d) The scatter between the CMIP2 models might not describe completely the uncertainty associated with how climate responds to radiative forcing. One example is the North Atlantic Oscillation. If it were to turn out that the NAO reacts more strongly to forcing in nature than in any of the models (which is tentatively suggested but by no means proven by recent observations), this might make all models underestimate the wintertime warming associated with increasing $\mathrm{CO}_{2}$.

It is very difficult to quantify these methodological uncertainties. As the authors of this paper we are tempted to think that they are relatively small compared to those parts of natural variability and modelrelated uncertainty that are captured by the analysis. However, the verification of this subjective view must wait until suitable methods have been developed to assess the missing uncertainties in an objective manner.

\section{Conclusions}

The last decade of the 20th century was warm and wet in Sweden, in comparison with the previous $30 \mathrm{yr}$. 
In this paper we have tried to assess in objective terms whether this should be regarded as a sign of anthropogenic climate change or just as an expression of natural variability. Due to the large natural variability on regional scales, such as in mean values for Sweden, the answer can only be given in probabilistic terms.

Model simulations suggest, after adjusting the results for differences between simulated and observed interannual variability, that the observed annual mean warming and the increase in annual precipitation both have a probability of $6-7 \%$ to occur by chance. Neither these values nor comparisons with the longer observational record allow us to disregard the possibility that the changes might have occurred as a result of (unforced or forced) natural variability alone. More likely, however, the observed changes resulted from a combination of natural variability and anthropogenic greenhouse gas forcing. Our model-based analysis suggests that about half of the $0.8{ }^{\circ} \mathrm{C}$ annual mean warming from 1961-1990 to 1991-2000 was of anthropogenic origin, as well as about $30 \%$ of the observed $6 \%$ increase in precipitation. Perhaps more interestingly, the presence of the anthropogenic forcing appears to have reduced substantially the amount of "good luck" required to produce the observed changes. For the observed increase in temperature (precipitation), our results suggests a $23 \%(14 \%)$ probability of occurrence from a combination of anthropogenic forcing and natural variability, in contrast to the $6-7 \%$ probability associated with natural variability alone.

Nonetheless, the observed changes from 1961-1990 to 1991-2000 were larger than the average modelestimated greenhouse gas forced climate changes. In particular, the winters in 1991-2000 were $2.0{ }^{\circ} \mathrm{C}$ warmer than the mean for the previous $30 \mathrm{yr}$, in contrast with a $0.5^{\circ} \mathrm{C}$ warming expected from the model simulations. This difference seems to be largely related to the behaviour of the North Atlantic Oscillation. The models simulate, on the average, little change in the $\mathrm{NAO}$ with increasing $\mathrm{CO}_{2}$, in contrast with the large observed shift toward the positive phase from 19611990 to 1991-2000. It is not yet clear whether this difference reflects primarily unforced climate variability, a deficiency in the models in their response to increasing $\mathrm{CO}_{2}$, or sources of external forcing excluded in the models.

In the coming decades, the accumulation of greenhouse gases in the atmosphere will continue, leading most likely to continued global warming. In the course of time, temperature and precipitation in Sweden are also expected to increase. However, uncertainty in re- gional climate projections is large, in the short term mainly due to the substantial natural variability. Our forecast for the decade 2001-2010 suggests that temperature and precipitation in Sweden will probably be relatively close to those in 1991-2000. However, we estimate a $95 \%$ (87\%) probability that the annual mean temperature (precipitation) in the ongoing decade will be higher than that for 1961-1990. Despite the simplifications in our analysis this is a remarkable result, since the mean values for 1961-1990 are still widely used as the operational definition of normal present climate.

\section{Acknowledgements}

All CMIP2 modeling groups are acknowledged for conducting and making available the simulations requested by the CMIP Panel. CMIP is supported and the model data are distributed by the Program for Climate Model Diagnosis and Intercomparison (PCMDI) at the Lawrence Livermore National Laboratory (LLNL). J. R. has been funded by MISTRA and SMHI within the Swedish SWECLIM programme. The helpful comments of two anonymous reviewers are also gratefully acknowledged.

\section{Appendix: Modification of the difference time series}

Let $f$ denote the difference in climate between a given decade and the previous 30-yr mean. An 80-yr model run gives, when sub-sampling with a 1-yr interval, 41 non-independent realisations of $f$. The mean of these is defined as

$m=\frac{1}{41} \sum_{i=1}^{i=41} f_{i}$,

the mean square as

$s=\frac{1}{41} \sum_{i=1}^{i=41} f_{i}^{2}$

and the variance as

$v=\frac{1}{41} \sum_{i=1}^{i=41}\left(f_{i}-m\right)^{2}=s-m^{2}$.

If the differences $f$ come from an underlying probability distribution ("population" of 10-yr minus 30-yr differences) with mean $M$, mean square $S$ and variance $V$, the expected value of $m$ is $M$ and that of $s$ is $S=$ 
$M^{2}+V$. However, the random variation in the sample mean $m$ makes the expected value of its square to exceed $M^{2}$ :

$\varepsilon\left(m^{2}\right)=M^{2}+X V$.

Conversely, because from eq. (A3) $\varepsilon(v)=\varepsilon(s)-$ $\varepsilon\left(m^{2}\right)$, the expected value of the sample variance is smaller than the population variance:

$\varepsilon(v)=M^{2}+V-\left(M^{2}+X V\right)=(1-X) V$.

When the yearly time series that the difference series $f$ is derived from consists of white noise (plus possibly a linear trend), Monte Carlo simulations indicate $X \approx$ 0.12 . More generally, $X$ depends on the autocorrelation structure of the data, but this dependence appears weak enough to be neglected in this study.

These statistical results come to use if there is a need to modify the original difference time series. In sections 4 and 5, two causes for such modifications are identified: suspected biases in the mean (due to too strong greenhouse gas forcing) and variance. In both cases, rational guesses exist for the ratio between the real population statistics and the statistics for the population of 10-yr minus 30-yr differences from which the difference time series $f$ arises. Let us denote these ratios as

$M^{\prime \prime} / M=A$

$V^{\prime \prime} / V=B$ where $M \prime \prime$ and $V \prime \prime$ are the mean and the variance of the unbiased population. In this study, $A$ is estimated by assuming that the climate response is directly proportional to the global mean radiative forcing, and $B$ by assuming that the ratio between the real and the simulated variability is the same on interannual and interdecadal time scales.

To remove the suspected biases, the difference time series $f$ is replaced with a new time series with a different mean and variance but otherwise the same structure

$f_{i}^{*}=A m+C^{1 / 2}\left(f_{i}-m\right), \quad 1 \leq i \leq 41$.

This modified series $f^{*}$ should be an unbiased sample of the supposed real population, in the sense that the probability distribution is the same. This requires that both the mean and the mean square of the series $f^{*}$ are unbiased estimates of their supposed real values. The former condition is directly fulfilled by eq. (A8). The latter leads to the equation

$\varepsilon\left(s^{*}\right)=A^{2} \varepsilon\left(m^{2}\right)+C \varepsilon(v)=A^{2} M^{2}+B V$.

Substituting into this eqs. (A4) and (A5) and using $X=0.12$ gives

$C=\frac{B-0.12 A^{2}}{1-0.12}$

where $C$ is the ratio between the modified and the original sample variances.

\section{REFERENCES}

Alexandersson, H. 2001. Homogenisation of climate data, difficult but necessary. In: Detecting and modelling regional climate change (eds. M. Brunet India and D. López Bonillo). Springer-Verlag, Berlin Heidelberg, 3-12.

Alexandersson, H. and Eggertsson Karlström, C. 2001. Temperaturen och nederbörden i Sverige 1961-1990. Referensnormaler - utgåva 2. SMHI Meteorologi No. 99, 71 pp (in Swedish).

Allen, M. R. and Tett, S. F. B. 1999. Checking for model consistency in optimal fingerprinting. Clim. Dynam. 15, 419-434.

Collins, M., Osborn, T. J., Tett, S. F. B., Briffa, K. R. and Schweingruber, F. H. 2002. A comparison of variability of a climate model with paleotemperature estimates from a network of tree-ring densities. J. Climate 15, 1497-1515.

Cubasch, U. and coauthors 2001. Projections of future climate change. In: Climate Change 2001. The scientific basis (eds. J. T. Houghton, Y. Ding, D. J. Griggs, M. Noguer, P. J. van der Linden, X. Dai, K. Maskell and C. A. Johnson). Cambridge University Press, Cambridge, 525-582.
Delworth, T. L. and Knutson, T. R. 2000. Simulation of early 20th century global warming. Science $\mathbf{2 8 7}$, 2246-2250.

Folland, C. K. and coauthors. 2001. Observed climate variability and change. In: Climate Change 2001. The scientific basis (eds. J. T. Houghton, Y. Ding, D. J. Griggs, M. Noguer, P. J. van der Linden, X. Dai, K. Maskell and C. A. Johnson). Cambridge University Press, Cambridge, 99-181.

Giorgi, F. and Fransisco, R. 2000. Evaluating uncertainties in the prediction of regional climate change. Geophys. Res. Lett. 27, 1295-1298.

Houghton, J. T., Ding Y., Griggs, D. J., Noguer, M., van der Linden, P. J., Dai. X., Maskell, K. and Johnson, C. A. (eds) 2001. Climate Change 2001: The scientific basis. Cambridge University Press, Cambridge, 881 pp.

Hurrell, J. W. 1995. Decadal trends in the North Atlantic Oscillation: regional temperatures and precipitation. Science 269, 676-679.

Kalnay, E. and coauthors. 1996. The NCEP/NCAR 40-year Reanalysis Project. Bull. Am. Meteorol. Soc. 77, 437-471. 
Kistler, R. and coauthors 2001. The NCEP/NCAR 50-year reanalysis: Monthly means CD-ROM and documentation. Bull. Am. Meteorol. Soc. 82, 247-268.

Meehl, G. A., Boer, G. J., Covey, C., Latif, M. and Stouffer, R. J. 2000. The Coupled Model Intercomparison Project (CMIP). Bull. Am. Meteorol. Soc. 81, 313-318.

Mitchell, J. F. B. and coauthors 2001. Detection of climate change and attribution of causes. In: Climate Change 2001. The scientific basis (eds. J. T. Houghton, Y. Ding, D. J. Griggs, M. Noguer, P. J. van der Linden, X. Dai, K. Maskell and C. A. Johnson). Cambridge University Press, Cambridge, 695-738.

Moberg, A. and Alexandersson, H. 1997. Homogenisation of Swedish temperature data. Part II: Homogenised gridded air temperature compared with a sub-set of global gridded air temperature since 1861. Int. J. Climatol. 17, 35 54.

Power, S., Tseitkin, F., Torok, S., Lavery, B., Dahni, R. and McAvaney, B. 1998. Australian temperature, Australian rainfall and the Southern Oscillation, 1990-1992: coherent variability and recent changes. Aust. Meteorol. Mag. 47, 85-101.

Räisänen, J. 2001. $\mathrm{CO}_{2}$-induced climate change in CMIP2 experiments: quantification of agreement and role of internal variability. J. Climate 14, 2088-2104.

Räisänen, J. 2002. $\mathrm{CO}_{2}$-induced changes in interannual temperature and precipitation variability in 19 CMIP2 experiments. J. Climate 15, 2395-2411.

Ramaswamy, V. and coauthors 2001. Radiative forcing of climate change. In: Climate Change 2001. The scientific basis (eds. J. T. Houghton, Y. Ding, D. J. Griggs, M. Noguer, P. J. van der Linden, X. Dai, K. Maskell and C. A. Johnson). Cambridge University Press, Cambridge, 349416.

Shindell, D. T., Miller, R. L., Smith, G. A. and Pandolfo, L. 1999. Simulation of recent northern winter climate trends by greenhouse-gas forcing. Nature 399, 452-455.

Stocker, T. F. and coauthors 2001. Physical climate processes and feedbacks. In: Climate Change 2001. The scientific basis (eds. J. T. Houghton, Y. Ding, D. J. Griggs, M. Noguer, P. J. van der Linden, X. Dai, K. Maskell and C. A. Johnson). Cambridge University Press, Cambridge, 417-470.

Stott, P. A., Tett, S. F. B., Jones, G. S., Allen, M. R., Mitchell, J. F. B. and Jenkins, G. J. 2000. External control of 20th century temperature by natural and anthropogenic forcings. Science 290, 2133-2137. 